Document downloaded from:

http://hdl.handle.net/10251/35451

This paper must be cited as:

Bonet Aracil, MA.; Capablanca Francés, L.; Monllor Pérez, P.; Díaz García, P.; Montava Seguí, IJ. (2012). Studying bath exhaustion as a method to apply microcapsules on fabrics. Journal of the Textile Institute. 103(6):629-635. doi:10.1080/00405000.2011.596665.

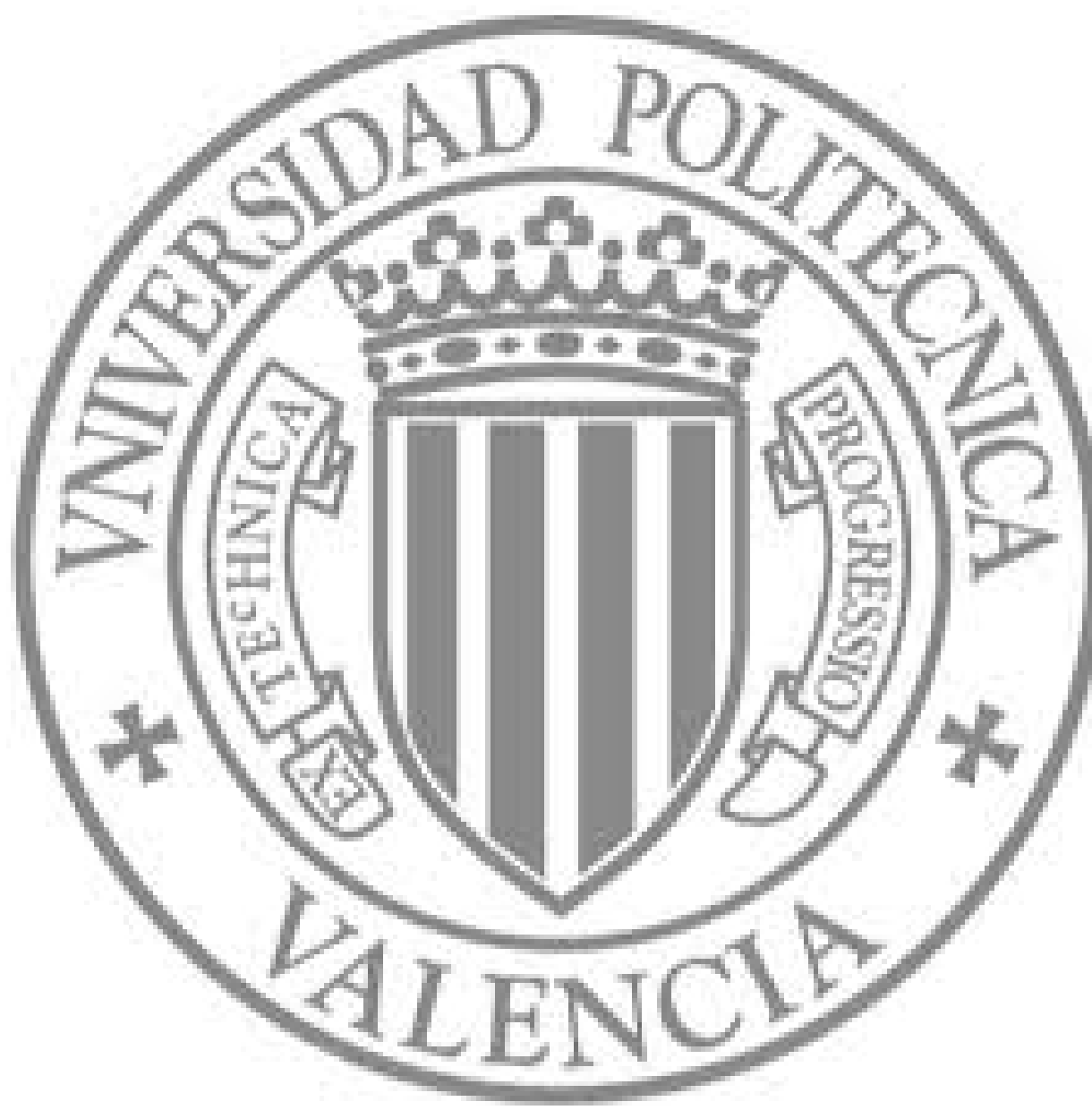

The final publication is available at

http://www.tandfonline.com/doi/pdf/10.1080/00405000.2011.596665

Copyright Taylor \& Francis: STM, Behavioural Science and Public Health Titles 


\title{
STUDING BATH EXHAUSTION AS A METHOD TO APPLY MICROCAPSULES ON FABRICS
}

\begin{abstract}
Microcapsules are widely used, being one of the fields which has increased their consumption the textile one. They can be applied to textiles using different methods such as, padding, bath exhaustion, spraying and foaming. Although the most extended industrial application is by padding commercial brands also suggest bath exhaustion as a possible procedure. In the research reported herein, bath exhaustion treatments are compared to padding. XPS (Photoelectronic spectroscopy of X-Rays) technique showed it was a suitable method to detect microcapsules presence on fabric surface. Results reported that high concentrations were required to obtain similar behaviours to those of padding. Moreover, we suggested reusing bath exhaustion baths, in order to minimise the loss of so much product in wastewater. We concluded it was not possible because microcapsules deflate when get in touch with water for a period of time, and what is more interesting, microcapsules preparation must be done just immediately before they are going to be used, so as to avoid microcapsules deflation due to contact with water.
\end{abstract}

\section{KEYWORDS}

Bath exhaustion, cotton, Microcapsules, padding, SEM, XPS . 


\section{INTRODUCTION}

Microcapsules products were born with carbonless copying paper (Zhang et al. 1999) and became very important in the pharmaceutical field (Stolnick, 1995). In other areas such as cosmetics (Gisbert et al, 2009; Kapunsiac et al, 2006) foods (Wegmuller at al. 2006), insecticides (Boh et al 2003; US Patent 2010/0183690 A1), and adhesives (Giroud et al, 1995), they are considered as a potential additive to improve their product properties. The main advantage of microcapsules is that new functions can be added. For example, since fragrance microcapsules are used, aromatherapy functions can be applied to textiles.

We can observe a wide variety of active products such as fragrances [ $\mathrm{Li}$ et al 2006; Nelson, 2001; Monllor et al 2007; Monllor et al , 2009; Monllor et al, 2010], phase change materials (Fan et al, 2004; Hawlader et al 2003; Xiao_Zheng et al 2003; Zhang et al 2004), dyes (Chang et al, 2003; Sawada et al, 2005), antimicrobial agents (Gisbert et al, 2009; Madene et al, 2006; Nelson, 2002; Wang et al, 2005) etc., which makes microcapsules an attractive field to study and of course patent applications have been increasing. Microcapsule shell is also varied (Madene et al, 2006; Nelson, 2002; Wang et al, 2005), but when it is based on oil materials, amino polymer resins such as melamine formaldehyde or urea formaldehyde have recently gained much attention due to the possibility of increasing oil shelf life and targeted delivery (Long et al, 2009). Moreover, active shell such as chitosan polymers can be found (Gisbert et al, 2009). 
When microcapsules are applied to textiles, commonly used shells are not reactive otherwise they would stick together. As a result of that chemical stability, no chemical reaction can be applied between microcapsule and fibre. Thus, in order to improve durability to washing or handle some auxiliary products it is required to join microcapsules to the fibre surface (Nelson, 2001); they are usually based on acrylic, polyurethanes, or silicone resins ( $\mathrm{Li}$ et al, 2008).

Knowing there is not enough affinity between microcapsules and fibres, a resin is needed to adhere them to the fibre and a mechanical process to help microcapsules to get into the fabric. Padding is one of the best known procedures to apply them in the textile field, however, commercial brands suggest some recipes depending on the procedure mainly padding or bath exhaustion, although foam is also an application system.

In order to characterise the microcapsules presence Scanning Electron Microscopy (SEM) has been commonly used since long ago (Nelson, 2002). However, it does not allow quantifying how many of them remain on fabric surfaces. XPS is a surface chemical analysis technique. It can be used to analyze the surface chemistry of a textile. Results offer information about the elemental composition. This technique will be used to quantify the presence of new atoms on cotton fabric. It was decided that the best method to adopt for this investigation was to apply microcapsules with melamine formaldehyde shell and use XPS technique to analyze the nitrogen presence on cotton fabrics. 
The aim of this paper is to evaluate the presence of microcapsules on fabrics depending on the application procedure. This study will try to demonstrate that bath exhaustion is not a feasible method to apply microcapsules onto fabrics. Firstly, it will compare padding to bath exhaustion as commercial brands suggest, and later on bath concentration and temperature will be modified in order to optimize the procedure.

\section{MATERIALS AND METHODS}

\subsection{Materials}

Microcapsules (CENTER FINISH 164/02 LAVANDA) were supplied by COLOR CENTER (Tarrasa, Spain). The wall material was melamine formaldehyde, and the microcapsules contained lavender fragrance. No further information was supplied by the provider, as companies disclose as little information as possible. In order to bond the microcapsules to the fabric, an acrylic resin was applied, also supplied by Color Center.

The fabric used was a $100 \%$ cotton twill fabric with $210 \mathrm{~g} / \mathrm{m}^{2}$, which had been chemically bleached with peroxide in an industrial process.

\subsection{Methods}

Commercial microcapsules were applied to the surface of the fabric by padding or bath exhaustion. In the finishing process a resin was used as a binder. As a 
result, thermal treatment in the form of hot air was applied to cure the resin and to induce microcapsules adhesion on the fibre surface. For padding a horizontal foulard was used. The bath treatment for padding had been studied previously (Monllor et al, 2009) and it was demonstrated that it should be comprised of 10 $\mathrm{g} / \mathrm{L}$ of resin and $60 \mathrm{~g} / \mathrm{L}$ of microcapsules. Foulard work was performed in order to obtain a pick-up (bath absorption) of around $89-90 \%$. This pick up is constant in our procedure, as it has been checked in every test through the years. With reference to bath exhaustion some samples $(10 \mathrm{~g})$ were treated on an open reactor with 1/40 liquor ratio, different concentrations of microcapsules and resins were used. Generally, commercial brands suggest $6 \%$ over weight of fibre (o.w.f), in this work different concentrations were tested $6 \%, 12 \%$ and 240 \% o.w.f for 40 minutes. Temperature influence was also tested (22ㅇ C, 60 $\mathrm{C}$ and $80^{\circ} \mathrm{C}$ ). All the samples were thermally dried in a scale pin stenter at $110^{\circ} \mathrm{C}$ for 10 min in WTC BINDER 030. Previously, it has been demonstrated that this temperature was high enough to polymerise the binder without evaporating the fragrance (Monllor et al, 2010). Table 1 summarises the treatment conditions herein studied.

\section{Insert table 1 about here}

\subsection{Scanning Electron Microscopy (SEM).}


For surface observation, a scanning electron microscope (SEM) Phenom microscope (FEl Company) was used. Each sample was fixed on a standard sample holder and sputter coated with a gold -platinum mixture. Samples were then examined with suitable accelerating voltage and magnification.

\subsection{X-ray Photoelectronic spectroscopy.}

The XPS spectra have been obtained with a VG-Microtech Multilab

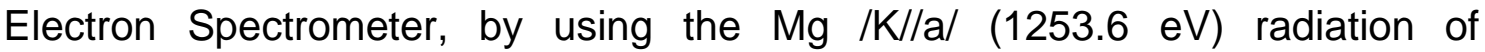
twin anode in the constant analyser energy mode with pass energy of 50 $\mathrm{eV}$. Pressure of the analysis chamber was maintained at $5 \cdot 10^{\wedge}-10 \mathrm{mB}$. The binding energy (BE) and the Auger kinetic energy (KE) scale were regulated by setting the $\mathrm{C} 1 \mathrm{~s}$ transition at $284.6 \mathrm{eV}$. The accuracy of $\mathrm{BE}$ and KE values was \pm 0.2 and \pm 0.3 , eV respectively. The $\mathrm{BE}$ and $\mathrm{KE}$ values were obtained by using the Peak-fit Program implemented in the control software of the spectrometer. XPS measurements were collected on 5 different zones of the fabric.

\section{RESULTS}

Knowing that commercial brands suggest applying microcapsules on fabrics by padding and bath exhaustion, this study tries to evaluate microcapsules behaviour during bath exhaustion treatment. In previous studies (Monllor et al, 2010) padding procedure was tested in order to obtain the optimum conditions for the padding process. As a result conclusions showed that in order to to reach up to 20 washing cycles keeping not only microcapsules on textile surface but their active function, $60 \mathrm{~g} / \mathrm{L}$ of microcapsules and $10 \mathrm{~g} / \mathrm{L}$ of acrylic 
binder was the optimum recipe. Thus, the work was focused on obtaining a bath exhaustion procedure in which similar quantities of microcapsules can be placed on fabric surface. The initial sample was prepared as the commercial brand's recipe suggests, using $6 \%$ of microcapsules and $1 \%$ of acrylic binder, temperature was $60^{\circ} \mathrm{C}$ as supplier suggests too. Figure 1 shows results of padded fabric. Figure 2 shows bath exhaust results, figure 2a matches with $6 \%$ of microcapsules and results of this study show little particles on fibres. In contrast to earlier findings by padding it was not enough and concentration was doubled (12\% microcapsules), results can be observed in figure $2 \mathrm{~b}$. The first set of analysis compare bath exhaustion with padding results, and it can be observed that the presence of microcapsules is insignificant on the fabric by bath exhaustion compared with the padded one.

\section{Insert figure 1 about here.}

\section{Insert figure 2 about here}

As a result the product concentration was increased considerably. Then, the same padding bath was used, which implies a concentration of $240 \%$ owf. The proportion of microcapsules that can be found on fabric can be seen in figure 3a. It shows a treatment by bath exhaustion at $60^{\circ} \mathrm{C}$. When fabric is observed a considerable increase in microcapsules concentration can be seen. In Figure $3 b$ and $3 c$ the influence of temperature on the treatment can be observed. It can be appreciated in figure $3 \mathrm{~b}$ that at room temperature $\left(22^{\circ} \mathrm{C}\right)$ low levels of microcapsules are on the fibre compared with temperature suggested by the supplier $\left(60^{\circ} \mathrm{C}\right)$. Figure $3 \mathrm{c}$ shows the results when treatment was at $80^{\circ} \mathrm{C}$. It is 
apparent from this observation that increasing the temperature above $60^{\circ} \mathrm{C}$ causes an insignificant increase in the amount of microcapsules on the fabric.

\section{Insert figure 3 about here}

If results from bath exhaustion (figure 3a) are compared with padding ones (figure 1), the most striking result is that the quantity of microcapsules in bath exhaustion is approximately the same or slightly higher, although there is not enough affinity between microcapsules and fibre and no reaction is possible. It is thought that this behaviour is due to the fact that the fabric works as a filter and it has been treated longer.

In order to quantify microcapsules presence on the fabrics, chemical surface composition has been studied by XPS technique. As cotton fibre has no nitrogen in its structure and supplier indicated microcapsules shell is made of melamine formaldehyde, then it is supposed that when microcapsules were placed on fabric, some nitrogen was added. When XPS analysis results were studied it was in order to observe chemical changes on fabric surface of non treated cotton compared with those in cotton when microcapsules were added either by bath exhaustion or by padding. Previously some authors [Rjibe et al, 2010; Topalovick et al, 2007; Zemljic et al 2009) analysed changes in cotton surface in terms of atomic contents of carbon, oxygen and nitrogen elements when treated with different products. Table 2 shows these atomic contents of the cotton fabric without treatment or with microcapsules. 
As nitrogen is the new element introduced in fibre by means of microcapsules presence, figure 4 shows XPS Peak-fit Program software analysis at this region. It can be appreciated that when no microcapsules are on the fabric (4a), Nitrogen region shows the same intensity than surrounding noise. On the contrary, when microcapsules are applied the nitrogen presence can be detected. It can be observed that padding results (4c) are slightly lower than by bath exhaustion (4b). The findings of the current study do support the previous statement about SEM results in which images allow to assure that behaviour, a higher quantity of microcapsules were detected on the fabric when bath exhaustion method was used.

These results therefore need to be interpreted with caution. Researchers are conscious that those concentrations are not usual in industry; moreover, wastewater will throw an important quantity of product which is not inexpensive. In order to check that statement, one drop from initial bath and from wastewater was taken and put on a paper. Figure 5 shows no difference between before (5a) or after (5b) the treatment was applied.

\section{Insert figure 5 about here.}

Taking into account that large quantity of microcapsules will be swept away in wastewater, reusing it may be a good choice. Some samples were treated with wastewater in the same way (60 $\cong \mathrm{C}, 40$ minutes, $\mathrm{r} / \mathrm{b} 1 / 40)$ and the samples offered similar behaviour. Thus, it will be a good chance to avoid wasting such a large quantity of products. Despite these findings, it could be observed that if 
microcapsules solution had been prepared for a period of time higher than 24 hours the microcapsule tends to lose spherical shape as they swell out, as it can be observed in figure 6 .

\section{Insert figure 6 about here.}

This means it is not possible to reuse baths for a long period, and it is somewhat surprising that, either by padding or by bath exhaustion, when applying microcapsules it should be recommended to prepare microcapsules

solution before it is applied to the fabric. The bath could be reused but for a period of time not higher than 24 hours otherwise, a large number of microcapsules would have lost their active compound.

\section{CONCLUSIONS}

First of all, the results of this investigation show that XPS technique is a suitable analysis to detect microcapsules on fabric surface when shell is composed of a polymer with nitrogen in its structure.

The present study was designed to determine the effect of two possible methods to apply microcapsules to a fabric; bath exhaustion and padding. When padding the mechanical force caused by cylinder pressure is what mainly places microcapsules on fabrics. If treatment is compared with bath exhaustion, it is noticeable that it is necessary to work with high concentrations of 
microcapsules and not only with the ones commercial brands suggested. Moreover, increasing temperature allows more microcapsules to be on the fibre surface. Yet, when temperature is over $60^{\circ} \mathrm{C}$, the effect is not significantly noticeable. Thereof, when working with microcapsules, temperature treatments should be as lower as possible; otherwise active product can be damaged.

The evidence from this study suggests that a high amount of microcapsules is swept away in wastewater. An implication of this is the possibility that wastewater could be reused. Some experiments were conducted in order to evaluate this and it could be found that it is not possible because when microcapsules are in touch with water for a long period of time they begin to swell and partially loose their active ingredient.

To sum up, when applying microcapsules to fabrics it is better to use padding to bath exhaust, as it needs fewer chemical products and can be used at room temperature.

\section{AKNOWLEDGEMENT}

Authors gratefully acknowledge the financial support received by this research project from the Spanish government in the program "Plan Nacional 20082011" reference Mat 2009-14210-C02-01. 


\section{REFERENCES}

Boh, B., and Kornhasuer, A. 2003. Reducing the Toxicity of Pesticides. Analytica. Chimica Acta ,33 ,281-284. DOI: 10.1080/714037677.

Chang, C.P., Yamamoto, T., Kimur Miho, S., Takashi, I. and Kimio, D. 2003. Release characteristics of an azo dye from poly(ureaurethane)Microcapsules. J. Controlled Release, 86, 207-211.

Fan, Y.F., Zhang, X.X., Wang, X.C. Li, J., and Zhu, Q.B. 2004. Supercooling prevention of microencapsulated phase change material. Thermochimica Acta, 413, 1-6.

Giroud, F., Pernot, J.M., Brun, H., Pouyet, B. 1995. Optimization of microencapsulation of acrylic adhesives. J. Microencapsulation,12, 389-400.

Gisbert, J., Ibañez F., Bonet, M., Monllor, P., Díaz, P. and I. Montava. 2009. Increasing hydration of the epidermis by microcapsules in sterilized products. Journal of applied polymer science, 113. 4, 22822286.

Hawlader, M.N.A., Uddin, M.S. and Khin,M.M. 2003. Microencapsulated PCM thermal-energy storage system. Applied Energy, 74, 195-202.

INSECT REPELLENT TEXTILE. US Patent 2010/0183690 A1

Kapusniak, J. Tomasik, P. 2006. Lipid microencapsulation in starch. J. Microencapsulation, 23,341-348.

Li, S., Lewis, J.E., Stewart, N.M., Qian, L. and Boyter, H. 2008. Effect of finishing methods on washing durability of microencapsulated aroma finishing. Journal of the Textile Institute99.2.177-183.

Long, Y., York, D., Zhang, Z. and Preece, J.A. 2009. Microcapsules with low content of formaldehyde: preparation and characterization. Journal of materials Chemistry, 19, 6882-6887

Madene, A., Jacquot, M., Scher, J., and Desobry S. 2006. Flavour encapsulation and controlled release - a review. Int. J. Food. Sci. Tech., 41.1, 1-21.

Monllor, P., Bonet, and M., Cases, F. 2007. Characterization of the behaviour of flavour microcapsules in cotton fabrics. European Polymer Journal, 43, 2481-2490.

Monllor, P., Capablanca, L., Bonet, M., Gisbert, J., Díaz, P., and Montava, I. 2010.Improvement of microcapsules adhesion to fabrics. Textile research journal, 80.7, 631-635

Nelson G., 2001. Microencapsulates in textile finishing Rev. Prog. Color. 31.57-64.

Nelson, G. 2002. Application of Microencapsulation in textiles. Int. J. Pharm., 242, 55-62.

P. Monllor, M. Bonet, L. Sanchez F. Cases. 2009. Thermal behaviour of microencapsulated flavours when applied to cellulosic fabrics. Textile research journal, 79.4, 365-380.

Rjiba, N., Nardin, M., Dream, J. Y. and Frydrych, R. 2010. Comparison of surface properties of different types of cotton fibers by inverse gas chromatography. Journal of Polymer Research, 17, 25-32. 
Sawada, K., and Urakawa, H., 2005. Preparation of photosensitive color-producing microcapsules utilizing in situ polymerization method. Dyes \& pigments, 65, 45-49.

Stolnik, S. 1995.Long circulating microparticulate drug carriers. Adv. Drug Delivery Rev, 16, 195-214.

Topalovic, T., Nierstrasz, V. A., Bautista, L., Jocic, D. Navarro, A., and Warmoeskerken, M. C. G. 2007. Analysis of the effects of catalytic bleaching on cotton. Cellulose, 14, 238-400.

Wang, C.X. and Chen, S.L..2005 Aromachology and its Application in the Textile Field. Fibres \&Textiles in Eastern Europe, 13, 6(54), 41-44.

Wegmuller, R., ZImmermann, M. B., Buhr, V. G., Windhab, E. J., and Hurrell, R. E. 2006 .Development, Stability, and Sensory Testing of Microcapsules Containing Iron, lodine, and Vitamin A for Use in Food Fortification J. Food Sci., 71, s181-s187.

Xiao-Zheng, L. Zhi-Cheng, T., Guang-Long, Z., Li-Xian, S and Tao, Z. 2004. Microencapsulation of $n$-Eicosane as Energy Storage Material. Chinese Journal of Chemistry, 22, 411- 414.

Zemljic, L., Strnad, S. O., and Sauperl, K.2009. Stana-Kleinschek. Characterization of Amino Groups for cotton fibers coated with chitosan. Textile Research Journal, 79.3, 219-226.

Zhang, X., Tão, X.,. Yick, K. and Wang, X. 2004 Structure and thermal stability of microencapsulated phase-change materials. Colloid Polym Sci, 282, 330-336. DOI 10.1007/s00396-003-0925-y.

Zhang, Z.,Saunders, R., and Thomas, C.R. 1999.Mechanical strength of single microcapsules determined by a novel micromanipulation technique. Journal of Microencapsulation, 16 (1), 117-124. 


\section{FIGURE CAPTIONS}

Figure 1.- Padded fabric with $60 \mathrm{~g} / \mathrm{L}$ microcapsules and $10 \mathrm{~g} / \mathrm{L}$ binder.

Figure 2.- Fabrics treated by bath exhaust at $60^{\circ}$ C. a) $6 \%$ owf. b) $12 \%$ owf.

Figure 3.- Bath exhaust application $240 \%$ owf. a) $60^{\circ}$ C. b) $22^{\circ}$ C. c) $80^{\circ} \mathrm{C}$.

Figure 4.- XPS Nitrogen content on different treated fabrics. a) Without microcapsules, b) padding procedure, c) bath exhaust procedure.

Figure 5.- Bath solution with microcapsules a) before treatment b) after treatment.

Figure 6.- A drop of microcapsules solution 48 hours after being prepared. 


\section{TABLES}

Table 1.- Bath exhaust conditions

\section{BATH EXHAUSTION}

$\begin{array}{lllll}\text { TEST } 1 & \text { TEST } 2 & \text { TEST } 3 & \text { TEST } 4 & \text { TEST } 5\end{array}$

Microcapsules concentration (o.w.f)

$12 \% \quad 240 \% \quad 240 \% \quad 240 \%$

Binder

$1 \%$

$2 \% \quad 40 \% \quad 40 \% \quad 40 \%$

concetration (o.w.f)

Bath Temperature $(\stackrel{\circ}{\mathrm{C}})$

60

$60 \quad 60$

22

80

Drying temperature $(\stackrel{\circ}{C})$

110

$\begin{array}{llll}110 & 110 & 110 & 110\end{array}$ 
Table 2.- Chemical composition (atomic contents of carbon, oxygen and nitrogen elements) of cotton fibre surfaces as measured by XPS.

\begin{tabular}{lcccc}
\hline SAMPLE & $\% \mathrm{C}$ & $\% \mathrm{O}$ & $\% \mathrm{~N}$ & \pm SD \\
& & & & $(\mathrm{n}=5)$ \\
\hline Cotton & & & & \\
Cotton + microcapsules padding & 75.61 & 24.39 & -- & 0.13 \\
Cotton + microcapsules Bath exhaustion & 74.86 & 23.74 & 1.39 & 0.27 \\
& & 21.09 & 4.34 & 0.16 \\
\hline
\end{tabular}




\section{FIGURES}

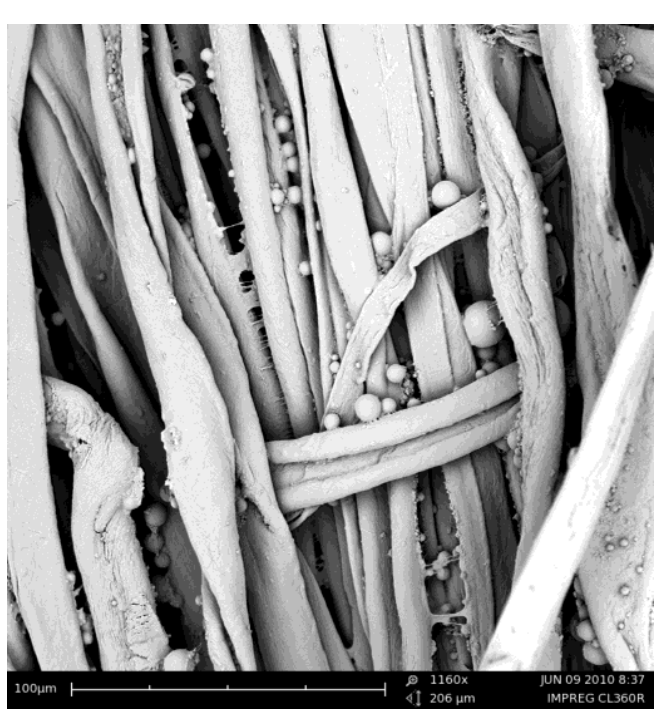

Figure 1.- Padding $60 \mathrm{~g} / \mathrm{L}$ microcapsules and $10 \mathrm{~g} / \mathrm{L}$ binder. 


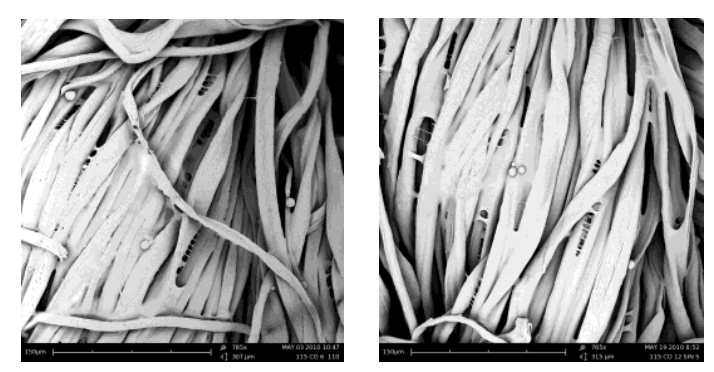

Figure 2.- Bath exhaustion samples, 60 ․ C. a) $6 \%$ owf. b) $12 \%$ owf 

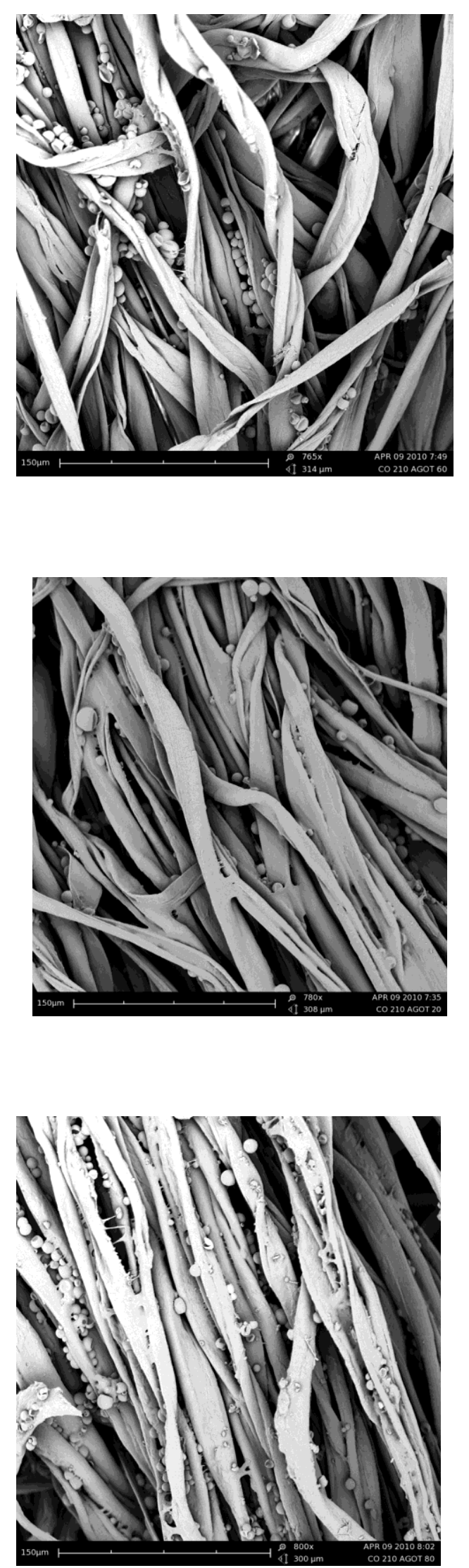

Figure 3.- Bath exhaustion application $240 \%$ owf. a) $60^{\circ}$ C. b) $22^{\circ}$ C. c) $80^{\circ} \mathrm{C}$. 


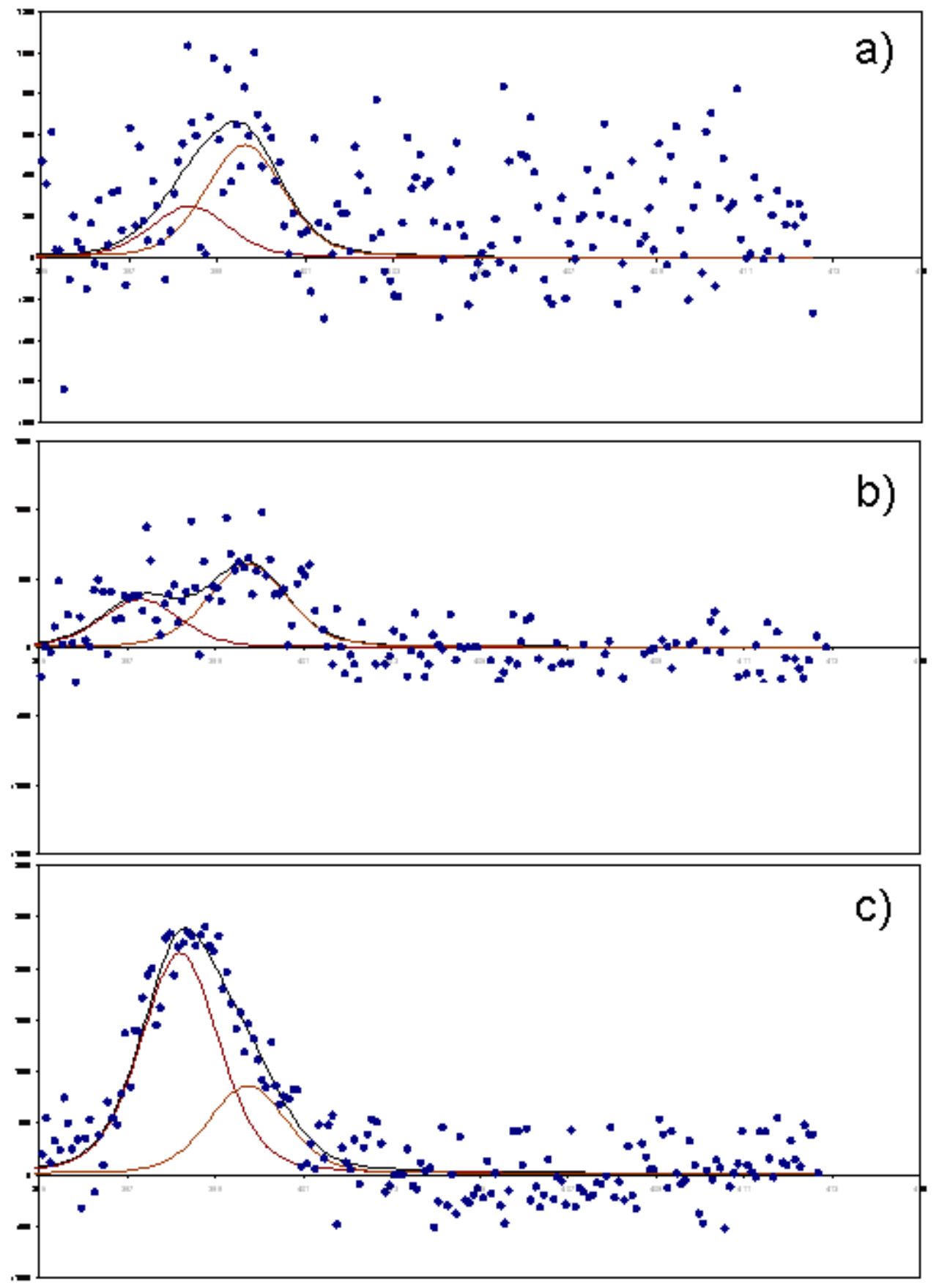

Figure 4.- XPS Nitrogen content on different treated fabrics. a) Without microcapsules, b) padding procedure, c) bath exhaust procedure. 

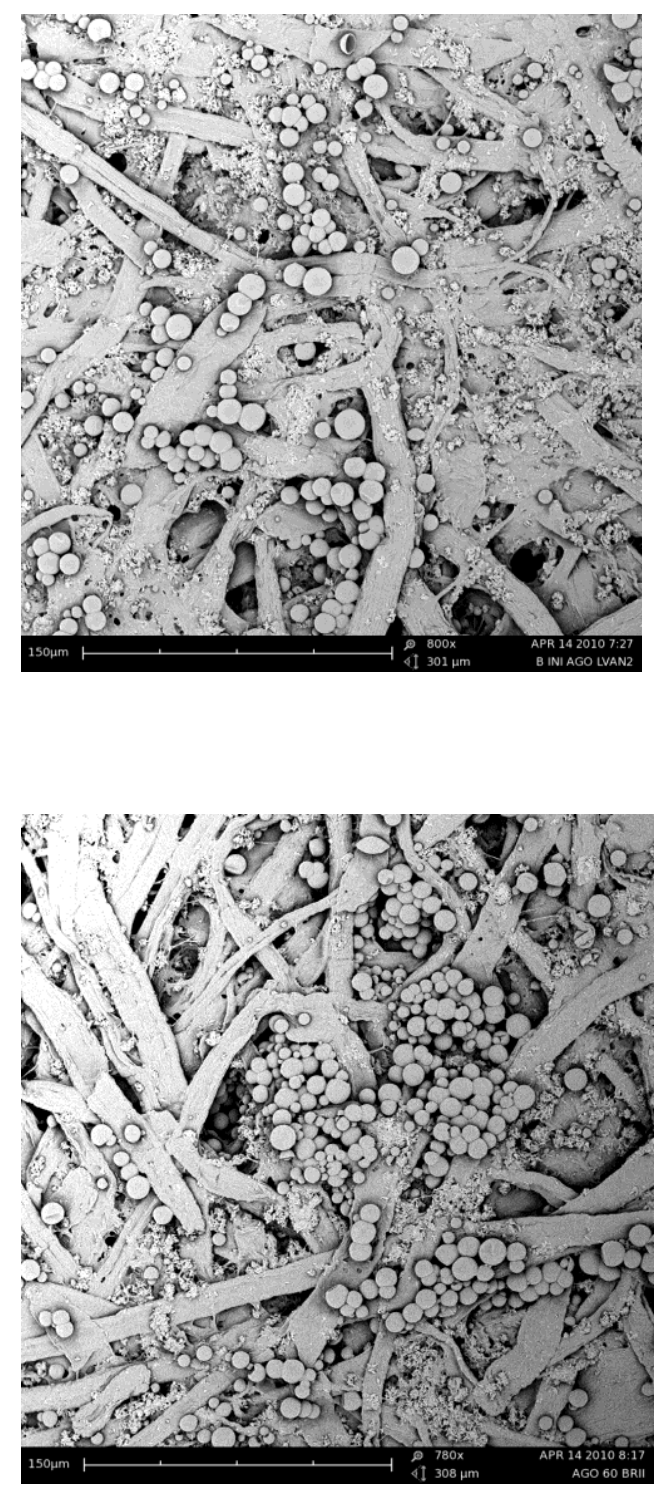

Figure 5. Bath solution with microcapsules a) before treatment b) after treatment 


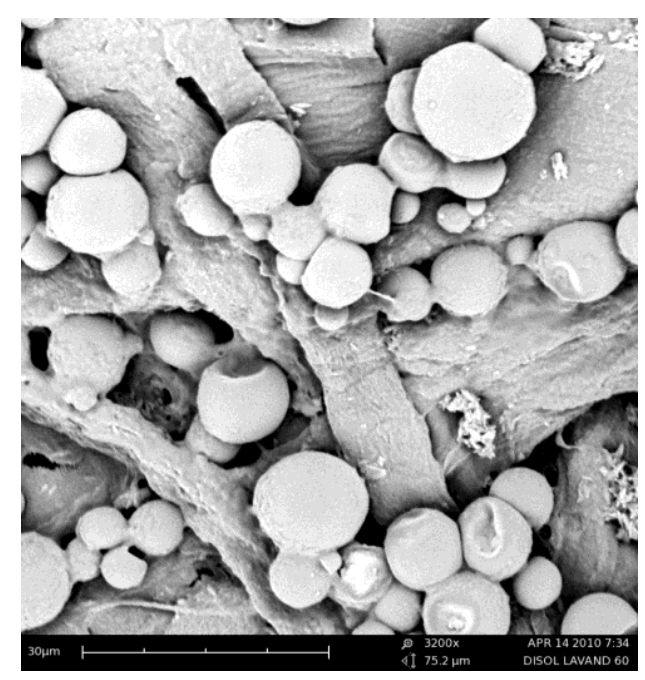

Figure 6.- A drop of microcapsules solution 48 hours after being prepared. 